Please cite this paper as follows:

Manfredi Latilla V., Frattini F., Messeni Petruzzelli A., and Berner M. (2018).

Knowledge management, knowledge transfer and organizational performance in the arts and crafts industry: a literature review.

JOURNAL OF KNOWLEDGE MANAGEMENT, vol. 22 (6), pp.1310-1331.

DOI: https://doi.org/10.1108/JKM-08-2017-0367 


\title{
Knowledge management, knowledge transfer and organizational performance in the arts and crafts industry: a literature review
}

\begin{abstract}
In the last decades, scholars have largely investigated the relationship between knowledge management and organizational competitiveness. More recently, knowledge transfer has become subject of academic interest, with specific regard to its relationship with organizational performance. This paper aims at providing a comprehensive academic literature review on the relationship between knowledge management, knowledge transfer and organizational performance, in a specific subset of the creative industry, i.e. arts \& crafts organizations. The creative industry represents an interesting area of investigation since it is closely related to the concept of knowledge-based economy, which has been gaining importance in academic research since the nineties, while arts \& crafts organizations have been gaining momentum only recently, i.e. starting from 2011 when scholars have started to deal in a systematic way with arts \& crafts organizational performance, emphasizing both the role of knowledge as a source of value creation, and the role played by craftsmen, the real knowledge owners in the process of value creation within arts \& crafts organizations. The paper also addresses other fundamental questions calling for further investigation, such as the analysis of the link between performance and "tacit knowledge" and the definition of new performance evaluation criteria to enhance the tacit knowledge of craftsmen as a real source of differentiation and competitive advantage for arts \& crafts organizations. The review concludes by summarizing the current state of research and suggesting an agenda for future research.
\end{abstract}

Keywords: knowledge management, knowledge transfer, organizational performance, arts \& crafts, creative industry, craftsmen.

\section{Introduction}

Since the eighties, scholars have started to study the role of competence, knowledge and organizational culture as critical success factors, paving the way to further academic research on change management and organizational behavior (Smirnich, 1983). More recently, research on the so-called "creative industry" has been gaining momentum among scholars, with a focus on the peculiarities and dynamics that characterize such industry (Messeni Petruzzelli and Savino, 2014; Boxenbaum and Battilana, 2005; Hirsch, 2000; Seltzer and Bentley, 1999). Indeed, starting from the nineties, scholars have investigated the concepts of creative industry and knowledge-based economy, emphasizing the role of knowledge as a primary resource of the modern economy and creative industry as the result of individual inspirations, abilities and talents, able to create wealth and employment through the generation and exploitation of intellectual skills and craftsmanship abilities. In this regard, the creative industry has acquired a relevant role in countries such as the UK, Italy and France, as it will be better explained later in this paper.

Therefore, it is worth analyzing the relationship between studies on knowledge management and knowledge transfer as factors of competitive advantage (Stock, Six and Zachari, 2013; Lord and Ranft, 2000; O'Reilly, Chatman, and Caldwell, 1991), and research on creative industry as a growing and dynamic business sector (Hennekam and Bennett, 2017; Lampel and Germain, 2016; Seltzer and Bentley, 1999), reflecting on the interconnection between these areas of research, with a specific focus on a subset of the creative industry, i.e. arts \& crafts organizations. To outline a general description of the creative industry, a good starting point is the definition given by the Creative Industries Task Force Mapping Document (2000), according to which the creative industry refers to "activities that have their origins in individual creativity, skill and talent and which have the potential for wealth and job creation through the generation and exploitation of intellectual property", to focus later on arts \& crafts organizations, a specific subset of the creative industry, mainly related to the production of high symbolic value artifacts, resulted of largely manual (handmade) processes obtained thorough the work of high skilled (masters) craftsmen. As per the definition of the Creative Industries Task Force Mapping Document (2000), arts \& crafts organizations refer mainly to the following list of activities: architecture, the art and antiques market, crafts, design, 
designer fashion, music, the performing arts, classic publishing. To the extent of the present literature review, the issue of knowledge transfer in arts \& crafts organizations gains importance compared to other possible and broader definition of creative industry, because in this specific setting products are mostly handmade, making the knowledge of high skilled craftsmen of extreme importance for organizational success, as well as knowledge transfer between master craftsmen and their team of assistants vital for organizational survival in the long run. Craftsmen, indeed, are real "masters of art", capable of using the "intelligence of the hand", the "passion of the heart" and the "creativity of the mind" (in other words, their "tacit knowledge" (Shils, 1981; Schein, 2004) to acquire an aura of excellence and to confer exclusivity to products that, thanks to their skills, enjoy a unique positioning in international markets (Sennett, 2008).

Despite the interest of many authors toward both knowledge and creative industry (Lampel and Germain, 2016; Seltzer and Bentley, 1999), there is a lack of studies aimed at linking systematically these two research areas (i.e., knowledge and creative industry). This is a relevant issue since knowledge in creative industry tends to manifest itself in a tacit way (Venkitachalam and Bush, 2012), that cannot be easily transferred because it is not expressed in an explicit form (Von Krogh, Ichijo and Nonaka, 2000) and mainly refers to the assumptions and values at the base of an organization's culture (Schein, 2004). Nevertheless, tacit knowledge has a real tangible impact on organizational behaviors and becomes a determinant of organizational performance, as noted by relevant literature (e.g., Nonaka and Teece, 2001; Schein, 1996; Byles, Aupperle and Arogyaswamy, 1991; Koberg and Chusmir, 1987; Barney, 1986.). Nevertheless, tacit knowledge is difficult to analyze and to connect to organizational performance, because it is not shared through structured communication flows, rather exists in the mind of individuals as the result of their working experience (Harlow, 2008). With this regard, organizational performance, for the sake of the present review, is intended as the achievement of organizational goals (Kotlar et al., in press) i.e. the goal of arts $\&$ crafts organizations of realizing unique and exclusive products that satisfy a specific niche of customers that appreciate the hand-made quality of the artifacts, their uniqueness and the value of the tradition and history that is embedded and reflected in each specific artifact. This goal can be only pursued thanks to the skills and ability of craftsmen able to realize exclusive, handmade products that enjoy a unique positioning in international markets. In this sense, craftsmen's (tacit) knowledge can be considered a real financial resource (Davenport and Prusak, 2000) so that underlining the value of craftsmen's knowledge and its transfer becomes relevant not only for the mere survival of arts \& crafts organizations, but also to foster their growth and market visibility. With this regard, knowledge pertaining to the past is increasingly recognized as a powerful and unique source of organizational performance (Messeni Petruzzelli and Albino, 2012), rather than as a source of inertia and rigidity (Barron, West and Hanna, 1994; Leonard-Barton, 1992): this applies specifically to arts \& crafts organizations, which leveraging on their reservoir of knowledge, traditions (both internal and related to the territory the organizations belong to) and on the skills of their craftsmen, are able to foster their growth and market visibility.

Considering the aforesaid, the proposed literature review aims at contributing in a methodical manner to provide a holistic reflection on the two areas of research (i.e., knowledge management and transfer; and research on creative industry as a growing and dynamic business sector, with a specific focus on a subset of the creative industry, i.e. arts $\&$ crafts organizations), at the intersection between knowledge, knowledge transfer and arts \& crafts organizational performance.

More generally, in a time where globalization demands for the relocation of production processes and technology automates several job tasks, the arts \& crafts industry may become a key factor of competitive advantage for many western countries, because the specific 
knowledge of high skilled craftsmen cannot be automated and executed by a robot or outsourced to third countries, since "handmade" requires unique skills and ability that cannot be easily replicated, imitated or standardized. As stated by the former French President Giscard d'Estaing ${ }^{1}$, "protecting and promoting the arts \& crafts, especially in France and Italy, is vital: we must be aware that, in the future, if there will be no evolution of our extraordinary movement of artistic creation and decorative crafts, we let arts and crafts sector die". This because the variegated world of arts \& crafts is a living reality, relevant, dynamic and extremely important not only for culture, but also for the economy of a variety of countries (Colombo, 2007). It is hence important to support the activities of the arts \& crafts industry, enabling and facilitating in a structured and systematized way the transfer of craftsmen's knowledge, since such (mainly tacit) knowledge mainly pertains to the traditions of the firm itself (Messeni Petruzzelli and Albino, 2012) and refers to the long-standing traditions and practices of certain communities, which have often been passed orally from generation to generation (Shils, 1981).

In the arts \& crafts industry, more than in the creative industry in general, the analysis of knowledge and knowledge transfer is important for its tacit connotation, though this kind of knowledge is hard to connect to performance results because it mainly exists in the mind of craftsmen as the result of their working experience (Høgseth, 2013). Based on these preliminary considerations, and building on the assumption that a proper literature review helps summarize existing literature and create a solid foundation for advancing knowledge (Webster and Watson, 2002, p. 12) the research question is aimed at understanding how in the arts \& crafts organizations knowledge and knowledge transfer can be systematized as a source of competitive advantage, focusing on their impact on organizational performance.

Academic contributions published over two periods are taken into considerations, with the first period (i.e., 1990-2000) that covers a decade when the concepts of creative industry and knowledge-based economy were developed; while the second period (i.e., 2000-2016), covers a period in which scholars have started to investigate how to effective transfer knowledge (very often in the form of "tacit knowledge") retained by master craftsmen in arts \& crafts organizations, and the critical role played by craftsmen for the performance of such organizations (e.g. Hogan and Coote, 2014; Jong-Ae, 2006; Nonaka and Teece, 2001; Nonaka, Toyama and Nagata, 2000).

Methodology and results are outlined in sections 2 and 3. Specifically, section 3 shows that, although for the last two decades the literature has analyzed the knowledge-based economy trying to link (tacit) knowledge to performance (e.g., Capaldo, Lavie and Messeni Petruzzelli, 2017; Katila, 2002), , only recently this approach has been applied to the creative industry and in particular to arts \& crafts organizations (Hennekam and Bennett, 2017; Huang, Hsieh and $\mathrm{He}, 2014)$. In section 4 the findings of the research are systematized and discussed, to conclude in section 5 by presenting the limitations of the literature review and suggesting possible directions for further research.

\section{Method}

This section discusses the approach used to review the knowledge management literature on knowledge transfer and organizational performance in the arts \& crafts industry. The paper follows the model suggested by Vom Brocke et al. (2009), since it is suitable to structure the accumulated knowledge in a specific domain through the principles of quality, relevance of the essay and methodological rigor. The literature review identifies publications of interest to researchers (in the data-gathering process) and then describes the choice of relevant publications for the preparation of the research report (Savino et al., 2017). This review

\footnotetext{
${ }^{1}$ Conference "La grande Europa dei mestieri d'arte" (23th october 2007, Cattolica University - Milan).
} 
follows a five-phases approach (Fig. 1) in order to be systematic, transparent and replicable (see also Greer and Lei, 2012; Meier, 2011; Thorpe at al., 2005).

\section{Insert Figure 1}

First phase: definition of the context (and scope) of the review. The scope of this review is to contribute to delve into the theme of knowledge and knowledge transfer within arts \& crafts organizations, and its relationship with organizational performance. The research focuses on both theoretical and empirical contributions, aiming at offering an overview of different lines of thought on the proposed subjects. For this reason, the review is organized in two steps: in the first step, the different lines of thought are analyzed; in the second step, the results deriving from the first step are ranked based on criteria that emerge from the research. The review cannot be considered exhaustive, since only sources and contributions considered significant to the research domain by the authors have been selected.

Second phase: identification of keywords. The selection of keywords aims at creating a concept matrix, as reported in table 1 . This selection is not an easy process because of the high number and diversity of relevant concepts in knowledge management literature and the different approaches and terminology adopted by different authors. Some studies, in fact, dwell on the definition of knowledge and knowledge creation (Argote, McEvily and Reagans, 2003; Nonaka, Toyama and Nagata, 2000; Nonaka and Takeuchi, 1995; Nonaka, 1994); while other studies contextualize knowledge within organizations by creating a close relationship between knowledge, knowledge transfer and organizational performance, in the sense that knowledge must be transformed into specific artifacts to exert an influence on business performance in a contest of high technological turbulence and market dynamism (De Massis et al., 2016; Stock, Six and Zachari, 2013). Other studies identify in people, called knowledge workers, the main architects of knowledge transfer, defining them the true advocates of organizational competitive advantage (Yildiz, 2014; Calantone, Cavusgil and Zhao, 2002). Based on these considerations, the list of keywords selected is formulated relying on the experience of one of the authors in this industry (who has led him to constantly interact with owners of arts \& crafts organizations for research purposes over the years), and on the confrontation with a review panel of three experienced academics in the field of knowledge management. The following are the selected keywords: "knowledge", "knowledge transfer", "performance" and "craftsmen", the latter to be considered a category of knowledge workers part of the arts \& crafts industry.

\section{Insert Table 1}

Third phase: literature search. This phase begins with the selection of journals and databases to analyze. Considering that the breadth of the research on knowledge in organizations has changed over time, by increasingly including interdisciplinary aspects (organization, technology, strategic management, human resources, psychology and so on), the literature review has been based on the exclusive use of databases. Indeed, an investigation through academic publications would have been too broad, due to the difficulty in conducting a selection of the sources of interest prior to conducting the research itself. For this reason, the most meaningful contributions have been selected by means of two primary search engines: JSTOR (JS) and Google Scholar (GS). JSTOR because it contains a large number of contributions sorted by title, abstract and full text, and it also allows to select texts according to their relevance and history (Sirmon, Hitt and Ireland, 2007). Google Scholar because it allows to perform a comprehensive review of the academic literature, showing the results in order of relevance. Then, the literature search has continued through a forward search (FWS), 
reviewing additional sources mentioned in the articles selected, and a backward search (BWS), reviewing references of the articles provided through keyword search.

For the reasons stated above, the analysis of keywords is related to two distinct periods: 19902000 (i.e., when for the first time scholars studied the concepts of creative industry and knowledge-based economy, developing research on this specific domain) and 2000-2016 (i.e., when early theoretical contributions on how to effective transfer the knowledge retained by master craftsmen in arts \& crafts organizations, and the critical role played by craftsmen for the performance of such organizations became available). The two periods under analysis correspond to two different stages of the research, which has been conducted throughout March-June 2017. In the first stage, a representative sample of papers has been collected using the criteria listed below to identify the connection between knowledge and knowledge transfer, and the linkage between knowledge and performance within arts \& crafts organizations: Using JSTOR, the contributions have been filtered to include only journals in English language that include both the term "knowledge" and "transfer" in the abstract ("knowledge" in the abstract AND "transfer" in the abstract) and that belong to the "Management \& Organizational Behavior" field of study. Then, filtering to include only the results relevant to the domain of interest of this review, the useful contributions were 47. Google Scholar has been used as a complementary search engine. From this second search, adopting the same filtering criteria presented above, 34 papers have been considered as relevant contributions; 19 of which had already been identified by the previous research in JSTOR.

After having analyzed the connections between "knowledge" and "transfer", the connections between "knowledge" and "performance" have been considered, referring to the selected time range and adopting the same filtering criteria above proposed, that is considering the contributions having "knowledge" and "performance" as keywords in abstract ("knowledge" in the abstract AND "performance" in the abstract). JSTOR returned 48 significant contributions, while Google Scholar added 15 contributions, 5 of which had already been selected by JSTOR.

In the second stage of the research, the keywords "knowledge", "transfer" and "performance" in the arts \& crafts organizations were the subject of investigation. For this reason, the previously selected keywords ("knowledge", "transfer", "performance") were linked to a new keyword: "craftsmen", since craftsmen are the knowledge worker, the "masters of art", identified as the key resource for the success of arts \& crafts organizations. Considering the relationship between "knowledge", "transfer" and "craftsmen" ("knowledge" AND "transfer" AND "craftsmen") in Google Scholar, 32 significant contributions were found, while JSTOR did not return any further contribution. This also applies to the relationship between "knowledge", "performance" and "craftsmen" ("knowledge" in the abstract AND "performance" in the abstract AND "craftsmen" in the abstract) which in the search with Google Scholar added 12 significant results, 4 of which had already been identified in the previous stage. Finally, a backward search and a forward search was conducted on 3 contributions (i.e., Argote and Fahrenkopf, 2016; Harlow, 2008; Chen and Chen, 2006) deemed of particular interest for their proposed research topic, arguments and references. The backward search added 9 contributions, while the forward search added 3 contributions. The research has reached a total of 172 results, an amount that can be considered sufficient to develop some relevant considerations about the proposed research question.

Table 2 reports the summary of the third phase. Figure 2 reports the articles resulting from the application of the proposed methodology and published between 1990 and 2016. This shows that the peaking years for the research on this topic were 2003-2004, with an upward trend in the last years. Interestingly, examining the journals in which the 172 articles were published, it emerges how widespread this topic is in the management literature. Indeed, these articles appeared in 52 different journals, mostly top-quality outlets such as Academy of Management Journal, Journal of Knowledge Management, Technovation, Strategic Management Journal 
and similar. Figure 3 reports the top- 10 journals for number of articles analyzed: these top-10 journals published 94 out of the 172 articles reviewed, more than half of the total contributions analyzed.

\section{Insert Table 2}

Based on the selected contributions, following the pattern of Vom Brocke et al. (2009) and using a concept matrix, the fourth phase of the research analyzes and synthetizes the results obtained, whose findings are described and discussed later.

Finally, to provide new tracks of research, the last phase of the literature review (the fifth phase of the Vom Brocke's model) focuses on defining the limits of the study by offering ideas useful for future research.

\section{Insert Figure 2}

Insert Figure 3

\section{Literature search outcomes}

The 172 papers obtained through the literature review have been placed in a concept matrix, where 12 criteria have been taken into account with the aim of creating a classification of different contents for further analysis. Specifically, these criteria are: the search code (column $A$ ), which is useful to assign to each selected criterion an ID number; references in the papers (title, author, journal / book, year, column B); abstract (column C); source (JSTOR and Google Scholar, column D) and possible backward search (column E) and forward search (column F). Finally, the contributions were characterized by two time-related variables [First period (1990-2000), column G; Second period (2001-2016), column H] and content-related variables, identified in the objective of the research (Knowledge, column I; People, column L; Performance, column $M$; Organizations, column $N$ ). Table 3 describes the structure of the concept matrix. The analysis of the four content-related variables (i.e., "knowledge", "people", "performance", "arts\&crafts organizations") is detailed in the following part of this Section 3.

\section{Insert Table 3}

The first content-related variable that has been matched to time-related variables is "knowledge". The conducted research shows that the debate related to "knowledge" started to be particularly lively from the year 2003 onward. Figure 4 shows that the highest attention on this variable emerged in 2003-2004. After about 5 years, i.e. from 2005 to 2010, of progressive lack of interest, starting from the year 2011 this theme of research has regained momentum.

\section{Insert Figure 4}

In 2003-2004 scholars started to analyze the impact of knowledge and knowledge transfer on the organizational strategic decisions and innovative outcomes (Chourides, Longbottom and Murphy, 2003; Bose, 2004; Hogan and Cote, 2014), underlining the role of tacit knowledge and emphasizing the centrality of people in the process of knowledge transfer (Tsoukas, 2003; Dhanaraj, Lyles, Steensma and Tihanyi, 2004; Venkitachalam and Busch, 2012). The themes analyzed refer to lines of thought already discussed, since previous research on the role of knowledge in organizations dates back to 1991, when Epple, Argote and Devadas (1991) argued that the analysis of knowledge transfer is critical to the proper understanding of the organizational learning level and its ability to generate change. Three years later, a scientific approach to the essence and composition of knowledge in organizations started to develop 
(Nonaka, 1994), defining knowledge in its double essence, constituted by two entities in a constant dialogue, the "tacit" and the "explicit" one. In the years 2000-2003 the analysis deepened, confirming the necessity of reaching a balance between the use of "explicit" and "tacit" knowledge (Tsoukas, 2003). This second type of knowledge especially attracted the attention of scholars (about $21 \%$ of the selected contributions), since tacit knowledge is a noncodified one, not mentioned in books or manuals, not managed through structured communication flows, that exists in the minds of individuals as the result of working experiences, and that is linked to the understanding of the contexts of action, feelings and insights that can hardly be understood by those who do not share that same working experience (Nonaka and Takeuchi, 1995).

After the year 2000, researchers started to analyze the need for a complete integration of knowledge in organizational processes (Alavi and Leidner, 2001) and, from 2004 onward, the role of knowledge workers in organizations and the theme of organizational performance became matter of primary importance (Ahn and Chang, 2004). Researchers, indeed, nowadays adopt expressions such as Knowledge Management System (Hislop, 2013), which had been proposed ten years before to represent a system designed to support the creation, application and, above all, the transfer of knowledge, considered the basis of organizational competitive advantage (Huang, Hsieh and He, 2014; Argote and Ingram, 2000).

Figure 5 reports the evolution of the debate related to "knowledge", which started to be particularly lively from the year 2003 onward.

\section{Insert Figure 5}

The second considered variable is "people", who lie at the core of the knowledge transfer process. The debate on the role of individuals in organizations began in the years 1992-1993, when for the first time it was investigated the need to invest in knowledge workers, not only as a source of creativity and innovation, but also as a factor of organizational success (Pulić, 1998; Nonaka, 1994). This debate intensified some years later, when Sveiby (1996), discussing about knowledge transfer as a key factor for organizational success, emphasized the role played by individuals, together with the concepts of creativity, confidence, innovation and reputation. Though, the role of individuals in the organization, especially in the knowledge transfer process, became central in the academic debate only starting from the year 2000, when Osterloh and Frey (2000) addressed the role that motivation plays in the performance of working tasks as a fundamental lever in the transmission of individual knowledge. Similarly, Argote and Ingram (2000) argued that the interaction between people, tasks and tools makes knowledge a competitive advantage, establishing a clear connection between the individual as a working entity, the organization as a group of people performing tasks and activities, and performance (see also, Argote and Fahrenkopf, 2016). Figure 6 shows that the highest attention paid to this variable emerged indeed around the year 2000, and peaked in 2004. After about 5 years (2005-2010) of progressive lack of interest, starting from the year 2011 this theme of research regained momentum; while Figure 7 reports the evolution of the debate related to "people", i.e., the debate on the role of individuals in organizations, which began in the years 1992-1993.

\section{Insert Figure 6 \\ Insert Figure 7}

The third variable identified is "performance". The concept of performance started to be analyzed by the academic literature only when both knowledge and the role of knowledge workers became relevant to obtain competitive advantage (De Gooijer, 2000). Few years later, in 2003, the concept of KPIs started to be subject of debate, being KPIs recognized as 
necessary tools for the analysis of the relationship between organizational performance and knowledge, to justify to the top management the necessity of investing in knowledge and training of employees (Del Rey Chamorro, Roy, Van Wegen and Steele, 2003; Chourides, Longbottom and Murphy, 2003). In particular, Ahn and Chang (2004) and more recently Yildiz (2014), supported the need to measure performance relevant to knowledge proposing a specific methodology (i.e., KP3 methodology), creating a practical guide to knowledge management. Figure 8 shows that the highest attention paid to this variable emerged in the years 2003-2004. After about 5 years, i.e. the period 2005-2010, of progressive lack of interest, starting from the year 2011 this theme of research regained momentum; while Figure 9 reports the evolution of the study on the concept of "performance", which became relevant starting from the year 2000, when both knowledge and the role of knowledge workers became relevant to obtain competitive advantage (De Gooijer, 2000).

\section{Insert Figure 8 \\ Insert Figure 9}

The fourth and last variable considered tries to shed light specifically on "arts $\&$ crafts organizations", though they captured only the $5 \%$ of the total contributions analyzed in the present review. The largest share of contributions on organizations, indeed, deals with technological firms, since technological knowledge is considered of extreme importance by scholarly research (Howell and Boies, 2004; Spencer, 2003; Chiesa and Manzini, 1998; Teece, 1997, 1992), followed by studies on manufacturing companies. Arts \& crafts organizations, with this regard, have been addressed for the first time in 2011 (Caira, Cross and Dunleavy, 2012; Høgseth, 2013), to become relevant in the academic research in the following years, when scholars started to deal with the theme of knowledge in the arts \& crafts industry, marking the difference between knowledge linked to manual skills, quality of work and virtues of craftsmen, and technological knowledge (Lampel and Germain, 2016; Bakshi and Windsor, 2015), and to investigate the theme of performance related to knowledge and knowledge workers (Yildiz, 2014). Figure 10 shows how in 2011 a specific interest in the study of arts \& crafts organizations arose. Before that moment $(2004 ; 2007 ; 2009)$, some authors reflected on the role of craftsmen in the knowledge economy by using a historical perspective, while some others offered a more updated view on the role of craftsmen in the knowledge economy. Finally, the most recent analysis on the role of knowledge in organizations stresses the need to promote organizational ecosystems able to create synergies between efficiency and creativity, to increase competitive advantages and sustainable value creation (Hennekam and Bennett, 2017). Figure 11 reports the evolution of the content-related analysis on arts $\&$ crafts organizations and knowledge in the arts \& crafts industry.

\section{Insert Figure 10}

Insert Figure 11

\section{Discussion}

The proposed literature review aims at discussing the relevance of knowledge management and knowledge transfer for organizations' performance, with regard to the context of arts \& crafts organizations. Accordingly, three main issues have emerged: i) how these organizations manage and transfer knowledge internally; ii) the effects of these activities on organizational performance; iii) the prominent role of craftsmen.

It is in the mid of the nineties that the theme of knowledge generation, management and knowledge transfer becomes relevant in research on management and organizational behavior. Pulić (1998), for example, stresses the need for organizations to efficiently and effectively locate, capture and share their knowledge and skills to maintain competitiveness. Seltzer and 
Bentley (1999) emphasize the role of knowledge as a primary resource of the "creative age" (as the authors define the current historical period), and analyze the internal profound changes the organizations require to survive this age. Specifically, they note that since the ' $90 \mathrm{~s}$, when the concept of knowledge-based economy has emerged, the creative industry in general has been gaining momentum: in the United Kingdom, for example, the number of creative organizations has shown a 34\% increase over the period 1990-2000. Furthermore, in 2001 the UK promoted the Creative Industries Task Force Mapping Document, which defines creative industry as "an activity born by the individual inspiration, abilities and talent and able to create wealth and employment through the generation and exploitation of intellectual property". The importance of this document lies in its goal of exploring and creating a new link between creative industry and traditional/manual sectors, such as arts \& crafts. As a matter of fact, Bakshi and Windsor (2015) fifteen years after the Creative Industries Task Force Mapping Document, have tried to answer to the question "why the UK needs one million new creative jobs by 2030 and what the government can do about that", showing that this topic, after almost two decades from its inception, is still actual and relevant. Osterloh and Frey (2000) identify knowledge, knowledge generation and knowledge transfer as essential for the acquisition of organizational competitive advantages, while Chen and Fong (2015) state that "knowledge management is a discipline possibly impacting organizational competitiveness and innovation”. Specifically, Tseng (2016) argues that, over the years, the evaluation of knowledge management has become increasingly important, since it can directly support strategic corporate decisions, eventually strengthening competitiveness.

\subsection{Knowledge transfer in arts \& crafts organizations: the prominent role of craftsmen}

With regard to the peculiarities of arts \& crafts organizations and the way they effectively manage and transfer knowledge internally, the majority of the selected articles mainly focus on knowledge from a technological perspective, ignoring the transfer of traditions and tacit knowledge, which belongs typically to arts \& crafts organizations. The contributions closer to the domain of research of the present review are those addressing the issue of knowledge transfer in the segment of small and medium-sized enterprises, businesses and manufacturing districts (e.g., Cerchione and Esposito, 2017; De Massis et al., 2016; Messeni Petruzzelli and Savino, 2014; Caira, Cross and Dunleavy, 2012; Giuliani, 2007; Grandinetti and Tobacco, 2004; Gudmundson, Tower and Hartman, 2003; Albino, Garavelli and Schiuma, 1998). Nevertheless, the osmosis between tradition and innovation appears to be an essential element for the identification of arts \& crafts organizations. Tradition, indeed, is a key element that allows firms to develop innovation characterized by uniqueness (Di Minin and Faems, 2013) building on firms' tacit knowledge resources, extensively validated and transferred over time, that allow to produce exclusive and unique products (De Massis et al. 2016; Heeley and Jacobson, 2008). This is particularly relevant for example in Italy where, with over $1,450,000$ active small businesses (or about $35 \%$ of total Italian companies) the tradition of arts \& crafts is robust and extremely important both in terms of export (18\% of the total export) and contribution to the national gross domestic product (Ministero dello Sviluppo Economico, 2014).

Furthermore, knowledge-based activities of (hand-made) craftsmanship are the primary functions within arts \& crafts organizations, at the very basis of the value creation process, having a huge impact on the creation of competitive advantage through the development of unique and exclusive handmade products. To this extent, an organization owning and managing effectively its knowledge, recognizing it as a critical resource to be transferred among employees and to the new generation, can build a solid and recognizable corporate and brand identity, leveraging on a unique heritage made of quality and creativity, to the point that knowledge can be considered itself as a real financial resource (Davenport and Prusak, 2000). 


\subsection{The relationship between "knowledge transfer" and "performance" in arts \& crafts organizations}

The recognition of arts \& crafts organizations as a resource for the economy and a source of creativity and innovation for the society is gaining importance in the academic debate, which recognizes the ability of such organizations to build on people and their skills, adequately considering craftsmen's tacit knowledge and its transfer process (Hennekam and Bennett, 2017; Lampel and Germain, 2016). Furthermore, the literature review shows how in arts \& crafts organizations there is a considerable link between the concepts of "performance" and "tacit knowledge". However, addressing such link is somehow hard to realize, mainly for the following reasons: $a$ ) the lack of awareness of the importance and relevance for the economy of the arts \& crafts industry; $b$ ) the low awareness among the same craftsmen and artisans of the uniqueness of their activity and role; $c$ ) the very small size of the vast majority of the arts $\&$ crafts organizations, which often makes very difficult for scholars to be conscious of both their presence on the territory and activities, which usually cover niche markets; lastly $d$ ) the common willingness of the organizations' owners not to disclose information related to the characteristics and peculiarities of their activities.

With regard to measurement of performance in arts \& crafts organizations, it has become an area of academic investigation only when both the role of knowledge management and transfer and the role of knowledge workers (i.e., craftsmen) became evident for obtaining a competitive advantage (Chen and Chen, 2005; Chourides, Longbottom and Murphy, 2003). Specifically, Ahn and Chang (2004) supported the need to measure performance relevant to knowledge proposing an ad hoc methodology able to achieve the ambitious goal of developing a theory of knowledge and a practical guide for its management. So far, several publications analyze the techniques for measuring business results and their relationship with knowledge management and transfer, as briefly reported in table 4 .

\section{Insert Table 4}

More specifically, Schindler (2015) and previously Harlow (2008) consider the link between performance and tacit knowledge feasible only when tacit knowledge can be measured through an index, known as the Tacit Knowledge Index. Harlow (2008) shows, for example, how a high level of tacit knowledge involves a high level of organizational performance in terms of innovation. This Tacit Knowledge Index would allow organizations to quantify the value of tacit knowledge, by itself difficult to encode, but a valuable source of differentiation and exclusivity specifically nowadays, when organizations are trying to manage knowledge as effectively and efficiently as possible to improve their performance.

\subsection{Concluding Discussion}

From the discussion, it emerges that nowadays scholars recognize the central role of knowledge and its transfer within a specific subset of the creative industry, the one represented by arts \& crafts organizations. The process of value creation in such organizations is mainly driven by craftsmen with a passion for quality work and the desire to improve skills and refine techniques to deliver a unique, tailor made and customized product with a very high value-added. Knowledge, in this regard, has been declared as a source of competitive advantage, an asset to be valued being closed related to performance results. However, analyzing the issue from a temporal point of view, it was found that the recognition in the academic literature of the centrality of knowledge and its transfer within arts \& crafts organizations is recent (from 2011 onwards). With this regard, this review has been an attempt to organize existing studies on knowledge management and transfer and to investigate the relationship existing between knowledge and performance in arts \& crafts organizations, in a time when scholars show a 
renewed interest in the study of arts \& crafts organizations and the way such organizations manage and transfer knowledge, and how this reflects on performance. Nevertheless, the relationship between knowledge and performance is yet to be explored, as well as the development of techniques for measuring arts \& crafts organizational performance effectively.

\section{Conclusions}

The results of the present review show an increasing interest in knowledge (even in its form of "tacit knowledge") and knowledge transfer into arts \& crafts organizations, where knowledge is recognized as a mixture of awareness, insights and feelings that characterize and make products unique, exclusive, innovative and timeless, as well as a source of organizational competitive advantage. These features are especially important during the current economic and historical phase, in which globalization requires economies to identify sources of differentiation to maintain a sustainable position in international markets. However, analyzing the topic with a historical perspective, it appears that the recognition in academic literature of the centrality of knowledge management and transfer within arts \& crafts organizations is only recent (i.e., from 2011 onward). Indeed, for approximately 20 years (i.e., 1990-2010) knowledge has been constantly related to technological paradigms and standardized results, with very little research and debate on craftsmanship and the role of craftsmen, whose activities were not considered value-added sources of knowledge and performance by both scholars and practitioners. Nevertheless, the research shows that over the years the focus on knowledge in arts \& crafts organizations and knowledge transfer has become progressively more detailed and precise, as summarized in table 5, outlining a more prominent role of craftsmen in the knowledge economy, explaining how, in sectors with a strong traditional background, the transfer of tacit knowledge is a meaningful challenge for many organizations (De Massis et al., 2016; Di Minin and Faems, 2013; Sveiby, 1997, 1996).

\section{Insert Table 5}

\subsection{Directions for future research}

The present review calls for a systematic reflection on how the transfer of traditional craftsmen's skills impacts organizational performances in the long run. Indeed, apart from very few studies (e.g., Schindler, 2015; Harlow, 2008), the definition and implementation of new performance evaluations criteria tailored to enhance the tacit knowledge of craftsmen as a real source of differentiation and competitive advantage for the arts \& crafts organizations is somehow still missing. The tacit knowledge indeed, in its essence of not-codified knowledge, which exists only in the minds of individuals as the result of their working experiences, and which is linked to their understanding of the contexts of action, feelings and insights that can hardly be understood by those who do not share that same working experience, requires a specific stream of research with focus on the activities of craftsmen and on the strictly related survival and evolution of arts \& crafts organizations. Tools such as Tacit Knowledge Index proposed by Harlow (2008) may be of great importance as a starting point to encode in performative terms what otherwise would be difficult to codify. This with the final intent of enabling arts \& crafts organizations to increasingly enhance the value of the knowledge of their craftsmen as an asset closely related to their performance in the modern market dynamics. Building on the previous considerations and on the examination of diverse literature throughout the developing on the present review, it has emerged the actual need for theoretical development and further studies on three main areas of research that currently represent a gap in the literature on knowledge management and transfer within arts \& crafts organizations. The following are the three main research gaps identified: (i) the need to address varying sources of tacit knowledge, its origins and evolution within arts \& crafts organizations; (ii) the need to address how tacit knowledge is transferred among different generation, and the specific role played by 
craftsmen in the transfer process; (iii) the need to investigate the relationship between knowledge transfer and performance in arts \& crafts organizations. These three main research gaps lead to the formulation of 10 research questions, reported in table 6 , which in the intent of the authors may bring to a deeper understanding of the role that knowledge transfer plays in the performance of arts \& crafts organizations, inspiring other scholars to continue the investigation on this area of research.

\section{Insert Table 6}

By pursuing its objectives indeed, this review aims to represent a step towards enabling arts \& crafts organizations to play a vital role in the modern society in a more structured way. This would help to build awareness of the potential of arts \& crafts organizations for promoting economic growth, proposing a value proposition different for the one dictated by the globalization and by the triumph of product standardization and mass production. With this regard, for example, France has acted as a pioneer, recognizing the value of craft of excellence since 2010, establishing the INMA (Institut National des Métiers d'Art), aimed at promoting crafts through various initiatives, supporting local businesses through a regional network of professionals and institutions, and exploring new areas where apply creativity in design, fashion and art. Therefore, promoting the variegated and dynamic world of arts \& crafts becomes crucial for protecting the peculiarities, tradition and knowledge of a variety of business ecosystems, made of craftsmen real masters of art, capable of using the "intelligence of the hand", the passion of the heart" and the "creativity of the mind" (Sennett, 2008) to confer exclusivity to products, while facing the competition of low cost substitutes or mass-market alternatives.

\section{References}

Abdullaha, N.H., Shamsuddin, A., Wahab, E. and Hamid, N.A.A. (2014). The Relationship between Organizational Culture and Product Innovativeness. Procedia - Social and Behavioral Sciences, 129, $140-147$.

Ahn, J.H. and Chang, S.G. (2004). Assessing the contribution of knowledge to business performance: the KP3 methodology. Decision Support Systems, 36(4), 403-416.

Alavi, M. and Leidner, D. (2001). Review: Knowledge Management and Knowledge Management Systems: Conceptual Foundations and Research Issues. Management Information Systems Research Center (MIS) Quarterly, 25(1), 107-136. Available at: http://www.jstor.org/stable/3250961.

Albino, V., Garavelli, A. and Schiuma, G. (1998). Knowledge transfer and inter-firm relationships in industrial districts: the role of the leader firm. Technovation, 19, 53-63.Argote, L. and Ingram, P. (2000). Knowledge Transfer: A Basis for Competitive Advantage in Firms. Organizational Behavior and Human Decision Processes, 82(1), 150-169.

Argote, L. and Ingram, P. (2000). Knowledge transfer: A basis for competitive advantage in firms. Organizational behavior and human decision processes, 82(1), 150-169.

Argote, L.; McEvily, B. and Reagans, R. (2003). Managing Knowledge in Organizations: An Integrative Framework and Review of Emerging Themes. Management Science, 49(4), 571-582.

Argote, L. and Fahrenkopf, E. (2016). Knowledge Transfer in Organizations: The Roles of Members, Tasks, Tools and Networks. Organizational Behavior and Human Decision Processes, 136(C), 146-159.

Bakshi, H. and Windsor, G. (2015). The creative economy and the future of employment. Why the UK needs 1 million new creative jobs by 2030 and what the government can do about it. Available at: https://www.nesta.org.uk/sites/default/files/the creative_economy and the future of employment.pdf [Accessed on June, $\left.20^{\text {th }}\right]$

Balconi, M. (2002). Tacitness, codification of technological knowledge and the organization of industry. Research Policy, 31(3), 357-379.

Barron, D.N., West, E. and Hanna, M.T. (1994). A time to grow and a time to die: growth and mortality of credit unions in New York City, 1914-1990. American Journal of Sociology, 100(2), 381-421. 
Barney, J. B. (1986). Organizational Culture: Can It Be a Source of Sustained Competitive Advantage? The Academy of Management Review, 11(3), 656-665.

Bhardwaj, M. and Monin, J. (2006). Tacit to explicit: an interplay shaping organization knowledge. Journal of Knowledge Management, 10(3), 72-85.

Boisot, M. (2002), The creation and sharing of knowledge. In Choo C.W. and Bontis N., The strategic management of intellectual capital and organizational knowledge, Oxford University Press.

Bose, R. (2004). Knowledge management metrics. Industrial Management \& Data Systems, 104(6), 457-468.

Boxenbaum, E. and Battilana, J. (2005). Importation as innovation: transposing managerial practices across fields. Strategic Organizations, 3, 355-383.

Byles, C., Aupperle, K. and Arogyaswamy, B. (1991). Organizational Culture and Performance. Journal of Managerial Issues, 3(4), 512-527.

Caira, T., Cross, B. and Dunleavy, K. (2012). Knowledge Transfer in Action within the SME Sector. $4^{\text {th }}$ European Conference on Management of Technology, Glasgow, Scotland. Available at: http://www.toktoc.eu/common/bibliography/2012 0419 TOK-

TOC Knowledge\%20Transfer\%20in\%20Action_EUROMOTPaper-V1.pdf [Accessed on July, $2^{\text {nd }}$ ]

Calantone, R.J., Cavusgil, S.T. and Zhao, Y. (2002). Learning orientation, firm innovation capability, and firm performance. Industrial Marketing Management, 31(6), 515 -524.

Capaldo, A. Lavie, D. and Messeni Petruzzelli, A. (2017). Knowledge maturity and the scientific value of innovations: the roles of knowledge distance and adoption. Journal of Management, 43(2), 503-533.

Cerchione, R. and Esposito, E. (2017). Using knowledge management systems: A taxonomy of SME strategies. International Journal of Information Management, 37(1), 1551-1562.

Chen, L. and Fong, P.S.W. (2015). Evaluation of knowledge management performance: an organic approach. Information \& Management, 52(4) 431-453.

Chen, M.Y. and Chen A.P. (2006). Knowledge management performance evaluation: a decade review from 1995 to 2004. Journal of Information Science, 32(1), 17-38.

Chen, M.Y. and Chen, A.P. (2005). Integrating option model and knowledge management performance measures: an empirical study. Journal of Information Science, 31(5), 381-393.

Chiesa, V. and Manzini, R. (1998). Organizing for Technological Collaborations: A Managerial Perspective. $R \& D$ Management, 28(3), 199-212

Chourides, P., Longbottom, D., and Murphy, W. (2003). Excellence in knowledge management: an empirical study to identify critical factors and performance measures. Measuring Business Excellence, 7(2), 29-45.

Colombo P. (2007), La grande Europa dei mestieri d'arte. L'artigianato artistico d'eccellenza nei paesi dell'Unione Europea, Vita e Pensiero, Milano.

Creative Industries Task Force. (2000), Creative Industries Task Force Mapping Document (CIFT), Department for Culture, Media and Sport, London. Available at: https://www.gov.uk/government/publications/creativeindustries-mapping-documents-2001.

Dhanaraj, C., Lyles, M.A., Steensma, H.K. and Tihanyi, L. (2004). Managing tacit and explicit knowledge transfer in IJVs: the role of relational embeddedness and the impact on performance. Journal of International Business Studies, 35(5), 428-442.

Davenport, T.H. and Prusak L. (2000). Working Knowledge, Harvard Business School Press, Cambridge, Massachusetts.

De Gooijer, J. (2000). Designing a knowledge management performance framework. Journal of Knowledge Management, 4(4), 303-310.

Del Rey Chamorro, F.M., Roy, R., Van Wegen, B. and Steele, A. (2003). A framework to create key performance indicators for knowledge management solutions. Journal of Knowledge Management, 7(2), 46-62.

De Massis, A., Frattini, F. Kotlar, J, Messeni Petruzzelli, A. and Wright, M. (2016). Innovation through tradition: lessons from innovative family businesses and directions for future research. Academy of Management Perspectives, 30(1), 93-116.

Dixon, N. M. (2000). Common knowledge: how companies thrive by sharing what they know, Harvard Business School Press, Cambridge, Massachusetts. 
Epple D., Argote L. and Devadas R. (1991). Organizational learning curves: a method for investigating intra-plant transfer of knowledge acquired through learning by doing. Organization Science, 2(1), 58-70.

Giuliani, E. (2007). The wine industry: persistence of tacit knowledge or increased codification? Some implications for catching-up countries. International Journal of Technology and Globalization, 3(2-3), 138-154.

Grandinetti, R. and Tabacco, R. (2004). Industrial districts in a knowledge-based perspective: the role of knowledge transfer and knowledge combination. Paper presented at the Conference on Clusters, Industrial Districts and Firms: the Challenge of Globalization, Modena. Available at: https://www.researchgate.net/profile/Raffaella Tabacco/publication/228724585_Industrial_districts in a know ledge-

based perspective the role_of knowledge transfer_and_knowledge_combination/links/00b495225a573eeada0 00000.pdf [Accessed on June, $15^{\text {th }}$ ]

Gregory, B. T., Harris, S. G., Armenakis, A. A. and Shook, C. L. (2009). Organizational culture and effectiveness: A study of values, attitudes, and organizational outcomes. Journal of Business Research, 62(7), 673-679.

Greer, C.R. and Lei, D. (2012). Collaborative innovation with customers: a review of the literature and suggestions for future research. International Journal of Management Reviews, 14, 63-84.

Gudmundson, D., Tower, C.B. and Hartman, E.A. (2003). Innovation in small businesses: culture and ownership structure do matter. Journal of Development Entrepreneurship, 8(1), 1-18.

Harlow, H. (2008). The effect of tacit knowledge on firm performance. Journal of Knowledge Management, 12(1), $148-163$

Hennekam, S. and Bennett, D. (2017). Creative industries work across multiple contexts: common themes and challenges. Personnel Review, 46(1), 68-85.

Hirsch, P.M. (2000). Cultural industries revisited. Organization Science, 11, 356-361.

Hislop, D. (2013). Knowledge Management in Organizations. Oxford University Press, Third Ed., Oxford.

Hogan, S. J. and Coote, L. V. (2014). Organizational culture, innovation, and performance: A test of Schein's model. Journal of Business Research, 67, 1609-1621.

Høgseth, H.B. (2013). Knowledge transfer: The Craftmen's abstraction. Project Muse 4, 9780816599301, 61-78.

Howell, J. M. and Boies, K. (2004). Champions of technological innovation: The influence of contextual knowledge, role orientation, idea generation, and idea promotion on champion emergence. The Leadership Quarterly, 15(1), 123-143.

Huang, X., Hsieh, JJ: and He, W. (2014). Expertise dissimilarity and creativity: the contingent roles of tacit and explicit knowledge sharing. Journal of Applied Psychology, 99(5), 816-30

Jong-Ae, K. (2006). Measuring the Impact of Knowledge Management. International Federation of Library Associations and Institutions (IFLA) Journal, 32(4), 362-367.

Katila, R. (2002). New product search over time: past ideas in their prime? Academy of Management Journal, 45(5), 995-1010.

King, W.R., Chung, T.R. and Haney, M.H. (2008). Knowledge Management and Organizational Learning. Omega, 36(2), 167-172.

Klamer, A. (2012). Crafting Culture: The importance of craftsmanship for the world of the arts and the economy at large. ACEI conference in Kyoto, Japan. Available at: http://klamer.nl/index.php/research-projects/crafts/218crafting-culture-the-importance-of-craftsmanship-for-the-world-of-the-arts-and-the-economy-at-large-arjoklamer-acei-conference-in-kyoto-japan-june-21-24-2012 [Accessed on July, $2^{\text {nd }}$ ]

Koberg, C.S. and Chusmir, L.H. (1987). Organizational culture relationships with creativity and other job-related variables. Journal of Business Research, 15(5), 397-409.

Kotlar, J., De Massis, A, Wright, M. and Frattini, F. (in press). Organizational Goals: Antecedents, Formation Processes and Implications for Firm Behavior and Performance. International Journal of Management Reviews.

Kun Chang, L., Sangjae, L. and In Won, K. (2005). KMPI: Measuring knowledge management performance. Information \& Management, 42, 469-482.

Lambooy, J.G. (2002). Knowledge and Urban Economic Development: An Evolutionary Perspective. Urban Studies, 36(5-6), 1019-1035. 
Lampel, J. and Germain, O. (2016). Creative industries as hubs of new organizational and business practices. Journal of Business Research, 69(7), 2327-2333

Leonard-Barton, D. (1992). Core capabilities and core rigidities: a paradox in managing new product development. Strategic Management Journal, 12(S1), 111-125.

Lord, M.D. and Ranft, A.L. (2000). Organizational Learning about New International Markets: Exploring the Internal Transfer of Local Market Knowledge. Journal of International Business Studies, 31(4), 573-589.

Martín de Castro, G., Delgado Verde, M., Navas López, J. E. and Cruz González, J. (2013). The moderating role of innovation culture in the relationship between knowledge assets and product innovation. Technological Forecasting \& Social Change, 80, 351-363.

McAdam, R., Mason, B. and McCrory, J. (2007). Exploring the dichotomies within the tacit knowledge literature: towards a process of tacit knowing in organizations. Journal of Knowledge Management, 1, 43-59.

Meier, M. (2011). Knowledge management in strategic alliances: a review of empirical evidence. International Journal of Management Review, 13, 1-23.

Messeni Petruzzelli, A. and Albino, V. (2012). When tradition turns into innovation. How firms can create and appropriate value through tradition. Oxford, UK: Woodhead Publishing Limited.

Messeni Petruzzelli, A. and Savino, T. (2014). Search, recombination and innovation: lessons from haute cuisine. Long Range Planning, 47, 224-238.

Ministero dello Sviluppo economico, Direzione Generale per la Politica Industriale, la Competitività e le Piccole e Medie Imprese (2014). Indagine sulle micro, piccole e medie imprese: sintesi dei principali risultati. Available at:

http://www.sviluppoeconomico.gov.it/images/stories/documenti/sintesindagine micro piccole medie impreseluglio2014.pdf. [Accessed on June, 21 ${ }^{\text {st }}$ ]

Muñoz van den Eynde, A., Cornejo Cañamares, M., Diaz Garcia, I. and Muñoz, E. (2015). Measuring Innovation Culture: Development and Validation of a Multidimensional Questionnaire. Advances in Research, 4(2), 122-141.

Nonaka I. (1994). A dynamic theory of organizational knowledge creation. Organization Science, 5(1), 14-37.

Nonaka, I. and Takeuchi, H. (1995). The Knowledge Creating Company, Oxford University Press, New York.

Nonaka I., Toyama R. and Nagata, A. (2000), A firm as a knowledge-creating entity: a new perspective on the theory of the firm, Industrial and Corporate Change, 9(1), 1-20.

Nonaka, I. and Teece, D.J. (2001). Managing industrial knowledge: creation, transfer and utilization, SAGE Publications, London.

O'Reilly III, C.A, Chatman, J. and Caldwell, D.F. (1991). People and organizational culture: A profile comparison approach to assessing person-organization fit. Academy of Management Journal, 34(3), 487-516.

Osterloh, M. and Frey, B.S. (2000). Motivation, Knowledge Transfer, and Organizational Forms. Organization Science, 11(5), 538-550.

Pulić, A. (1998). Measuring the performance of intellectual potential in the knowledge economy, 19th Annual National Business Conference / Carver Tiffany. Hamilton, Stahlke, Jennifer (ed.), Ontario, Kanada.

Rodgers P. A., Caldwell, N. H., Clarkson, J. and Huxor, A. (2000). Managing knowledge in dispersed design companies. Facilitating context - driven design support through multiple perspectives. In J. S. Gero, Artificial intelligence in design '00, Kluwer Academic Publishers.

Savino, T., Messeni Petruzzelli, A. and Albino, V. (2017). Search and recombination process to innovate: A review of the empirical evidence and a research agenda. International Journal of Management Reviews, 19, 5475

Schein, E. H. (1996). The missing concept in organization studies. Administrative Science Quarterly, 41(2), 229240.

Schein, E. H. (2004). Organizational culture and leadership. New York: John Wiley \& Sons.

Schindler, J. (2015). Expertise and Tacit Knowledge in Artistic and Design Processes: Results of an Ethnographic Study. Journal of Research Practice, 11(2), Article M6.

Seltzer K. and Bentley T. (1999). The creative age: knowledge and skills for the new economy. Demos, London. Sennett R. (2008), The Craftsman, Yale University Press, New Haven. 
Shils, E. (1981). Tradition. Chicago: University of Chicago Press.

Sirmon, D.G., Hitt, M.A. and Ireland, R.D. (2007). Managing firm resources in dynamic environments to create value: looking inside the black box. Academy of Management Review, 32(1), 273-292.

Smircich, L. (1983). Concepts of Culture and Organizational Analysis. Administrative Science Quarterly, 28(3), 339-358.

Smith, E.A. (2001). The role of tacit and explicit knowledge in the workplace. Journal of Knowledge Management, 5(4), 311-321.

Spencer, J.W. (2003). Firms' Knowledge-Sharing Strategies in the Global Innovation System: Empirical Evidence from the Flat Panel Display Industry. Strategic Management Journal, 24(3), 217- 233.

Stock, R., Six, B. and Zachari, N. (2013). Linking multiple layers of innovation-oriented corporate culture, product program innovativeness, and business performance: a contingency approach. Journal of Acad. Marketing Science, 41(3), 283-299.

Sveiby, K.E. (1996). Transfer of knowledge and the information processing profession. European Management Journal, 114(4), 379-388.

Sveiby, K.E. (1997). The new organizational wealth: managing \& measuring knowledge-based assets, Berret Koehler Publisher, San Francisco.

Teece, D. J. (1992). Competition, Cooperation, and Innovation: Organizational Arrangements for Regimes of Rapid Technological Progress. Journal of Economic Behavior and Organization, 18(1), 1-25.

Teece, D. J., Pisano, G. and Shuen, A. (1997). Dynamic Capabilities and Strategic Management. Strategic Management Journal, 18(7), 509-533.

Thorpe, R., Holt, R., Macpherson, A. and Pittaway, L. (2005). Using knowledge within small and medium-size firms: a systematic review of the evidence. International Journal of Management Review, 7, 257-281.

Tseng, S.M. (2008). Knowledge management system performance measure index. Expert Systems with Applications, 20(3), 734-745.

Tseng, SM. (2016). Knowledge management capability, customer relationship management, and service quality. Journal of Enterprise Information Management, 29(2), 202-221

Tsoukas, H. (2003). Do we really understand tacit knowledge? In E.-S. M. \& L. M. A., The Blackwell handbook of organizational learning and knowledge management, Backwell Publishing.

Tsoukas, H. (2005). Complex knowledge: studies in organizational epistemology. Oxford University Press.

Venkitachalam, K. and Busch, P. (2012). Tacit knowledge: review and possible research directions. Journal Of Knowledge Management, 16(2), 356-371.

Vom Brocke, J., Simons, A., Niehaves, A., Riemer, K., Plattfaut, R. and Cleven, A. (2009). Reconstructing the giant: on the importance of rigor in documenting the literature search. European Conference on Information Systems (17th ECIS), Verona (Italy). ECIS 2009 Proceedings.

Von Krogh, G. Ichijo, K. and Nonaka, I. (2000). Enabling knowledge creation. How to unlock the mystery of tacit knowledge and release the power of innovation. New York: Oxford University Press.

Webster, J. and Watson, RT. (2002). Analyzing the past to prepare for the future: writing a literature review. Management Information System Quarterly, 26(2), 13-23.

Yıldiz. E. (2014). A Study on the Relationship between Organizational Culture and Organizational Performance and a Model Suggestion. International Journal of Research in Business and Social Science (IJRBS), 3(4), 52-67. 